\title{
Has Internet Changed Anything in Advertising?
}

UDC: $004.738 .5: 659.1$

DOI: 10.7595/management.fon.2014.0020

In this paper we shall consider grosso modo actual opinions regarding advertising and advertising ethics. The emergence of the Internet aroused hope that advertising ethics is not the ultimate oxymoron (Beltramini, 2003). In spite of a negative connotation that postmodernism and globalization added to advertising theory and practice, the appearance of the Internet has really changed business philosophy regarding advertising and emphasized its ethical dimension. Results of our research confirm this thesis.

Keywords: advertising, ethics, postmodernism, globalization, Internet

\section{Introduction}

In recent years, advertising has been one of main preoccupations of business ethics. Is it directed only towards informing prospective customers and clients about a product or service or has it got more hidden ambitions - to create new desires? To what extent is advertising a fertile soil for manipulating the customer desires? The advance of the Internet has intensified the problem which was present even in the conventional ways of advertising. What makes customers unwilling to press the "purchase click"? Is that a lack of confidence not only in the purchase through the Internet but also in the Internet in general as a new "technological miracle"? Transactions through the Internet are characterized by a high level of uncertainty, anonymity, lack of control and possible opportunism, making the risk and confidence the crucial elements of e-business.

The competition on the e-market is severe and customers are bombarded by a large number of conflicting advertisements even about similar products. The possibilities for unethical advertisers' behavior are endless. The consumer cannot check the products or services personally and does not know what the seller (advertiser) will do with his/her personal data. There is a low certainty that the consumer will get the things they have seen on the screen, especially regarding the terms of delivery and the quality and quantity of product/service they ordered. As advertising by Internet is not directed only towards enlarging the cognitive sources but also towards provoking consumers' desires, one cannot but use a mental cut such as confidence as a mechanism for decreasing the complexity of human behavior in situations of high uncertainty. However, confidence is a complex, dynamic and multi-layered concept and there is no generally accepted definition about what it really encompasses. Building consumers' confidence is a conditio sine qua non of successful advertising by Internet.

Advertising is not the only, however, it certainly is the most important marketing device. It is an important constituent of promotive organizational activities. It is imperative for modern business and therefore it is amazing that a great deal of debates that surround it are running according to a disjunctive principle - for or against advertising. Such polarization is being supported by the critics of advertising who stress that advertising encourages exaggerated consumerism, even indebtedness, that it extols material values, fattens greed and acquisition, deludes and leads into wrong conclusions; that it is too repetitive and aggressive and treats public as an immature (intellectually inferior) mass, etc. As the end of advertising would mean the end of market economy in its mass consumer pattern, the right question is not whether to advertise or not but where the limits of morally acceptable advertising are?

This time we shall not repeat debates on advantages and shortcomings of advertising that started with a wellknown Packard's book (Packard, 1957). We shall skip the famous debate between John Kenneth Galbraith and Friedrich A. Hayek (Hayek, 1961) and ignore Beauchamp's standing about manipulative advertising (Beauchamp, 1988). The focus of our research will be on the contribution of postmodernism, globalization and the Internet revolution to the everlasting debate about good and bad sides of advertising. 


\section{Postmodernism and advertising}

Contemporary cultural inquiries most often describe modern society as a "consumer" society - to which consumption does not give only the meaning and identity but increasingly dominates over other aspects of social life: politics, education, health system and personal relations (Baudrillard, 1997). Baudrillard condemns Galbraith's "moralizing idealism" and his description of consumer as a passive victim of the system. He claims that the consumer is an active actor in the system who longs for satisfaction of his/her real needs for a social identity and differentiation through consumption.

The main Baudrillard's thesis is that advertising today, because of its disproportion, is not a mere addition to a system of objects, but is inseparable from it. It represents a functional apotheosis of the system; the system as much as deifies itself. Advertising is useless and needless and, as pure connotation, does not contribute at all to either production or practical use of things. It becomes the object of consumption. So, advertising can be seen as twofold: as a discourse about an object and as an object by itself. The discourse that is needless has to be spent like an object of culture. What is embodied through advertising is "the entire apparatus of personalization and imposed differentiation; of proliferation of the inessential and subordination of technical requirements to the requirements of production and consumption; of dysfunctionality and secondary functionality" (Baudrillard, 2005).

The informative side of advertising discourse and its rhetoric are not crucial for consumers. They do react to protection and pleasantness that are in its base, to signs that cannot be consciously riddled but should inform them about their own wishes. Advertizing has to predict and rationalize these wishes providing pleasantness and satisfaction for consumers.

In a society in which everything is subjected to the law of profit, advertising is, as it were, the most democratic product, it is the only thing obtained for free and it is free for all. Products and services are sold, only advertising is offered for free. It is obvious that advertising and the implicated choice transform commercial, sales relations to personal ones. Products and services cannot exist psychologically without the support of advertising. On the other side, without this offer, citizens would not be free. Advertising is a measure of collusion, emotional as much as ideological, between an individual and a society. Without advertising, individuals will feel frustrated.

The industrial society cuts the connection between labour and its product. Advertising radicalizes this split: it causes the product not to be seen anymore as such but as a commodity, as an object. The consumer does not see the social history of the product, he/she cannot see the real system of production and exploitation. As a discourse, advertising gives assistance to the political discourse whose demagogy is based on splitting the social reality into real organization and the picture of it in the way that the former is drowned in the latter. When advertising says that the society is totally adjusted to us and that we should completely integrate ourselves into the society - this is an evident deception: what is really adjusting is the picture of the product (society) and we are asked to adjust us to the real product (society) (Baudrillard, 2005). Advertising steps forward as a substitute for moral and political ideology. Moreover, if the later has frequently been imposed by force through the history, advertising techniques need not use force - consumer himself/herself internalizes the norms of social control through the consumption process.

\section{Globalization and advertising}

Not only advertising but also all segments of marketing are permeated by globalization. People from all countries and cultures are exposed to thousands of advertisements and promotions on a daily basis. However, confidence in advertising is not the same all over the world. Asians believe in advertising the most, while Russians are the most cynical regarding the same. But only $38 \%$ people say that advertisers offer true information to consumers and merely $30 \%$ believe that advertisers respect the consumers' intelligence (Belgiovani, 1996).

Globalization brings some problems to consumers as active participants of organizational life. Here we have in mind the reproduction of consumerism, transposition of production and consumption, cultural homogenization and new forms of resistance (Crane \& Matten, 2007). Promoting products and brands that are prac- 
tically inaccessible for most consumers in developing countries multinational companies reproduce a broader dissatisfaction than it is the case in developed countries. The promotion of consumerism is justified by economic arguments of utilitarian ethics: increased demand leads to economic growth that, in the final instance, brings benefit to all. Globalization is the main cause of homogenization and erosion of diversity. Standardization and uniformity are increased and cause a resistance in consumers who do think about unethical and irresponsible activities of multinational companies.

Globalization also contributes to emerging of the notion of ethical consumer. Ethical consumers can serve as a social control of business to some extent. If they demand business ethics to be improved through the market, it is expected from the businesses to respond to this demand and to listen to the voice of consumers. In this case the consumer uses his/her "vote" to support or criticize some business practices and this vote is called customer citizenship (Dickinson \& Carsky, 2000).

Laymen and professionals all over the world maintain that successful advertising campaigns are mediated by popular cultures and daily creation of meanings. Marketing communications are penetrating secretly into the consciousness of consumers using cultural symbols through which people can take part in socially constructed meanings. This, of course, is quite opposite to the deep-rooted opinion that marketing and advertising culture are morally injurious by themselves. If ethical questions regarding marketing communications and advertising (such as general moral degradation, greedy individualism, consumers' avidity, hedonism, glorification and trivialization of sex and violence etc.) are social constructions, then globalization brings to light the essential question: if something is wrong in consumerism and consumers, why is it wrong and who is responsible for that (Hackley, 1999)?

\section{Internet revolution and advertising}

The first e-mail message had been sent 40 years ago. From that time e-mail has been the most used application on the Internet. However, as a new advertising device, the Internet set up the following dilemma: you can market intrusively, moving into consumer's space uninvited, or you can market with the permission of the consumer. Consumers have become more sensitive regarding unwanted messages. Therefore advertisers try to establish permanent relations with consumers and are very conscious about their sensitivity. That is to say that they have to worry about two things: the attitudes of customers and the laws.

The result of controlling consumers' attitudes is that the advertiser ensures that consumers are sent what they really expect to receive and what is relevant and useful. It is necessary for the advertiser to provide an easy way for consumers to go out from each message and to unsubscribe from the list if they feel disturbed. This two-way communication between advertisers and consumers lead to the creation of the best ethical practice of advertising by Internet. These are some of the principles of that practice: "1) provide truthful message headers, subjects and content; 2) provide an obvious, simple unsubscribe process (one click is ideal); 3) always actually de-list those who wish to unsubscribe; 4) provide the physical address of the sending company; 5) provide an accessible, transparent privacy policy; 6) use opt-in addresses only, ideally double optin, and never use opt-out addresses; 7) never use third-party lists unless you know they are opt-in; 8) if your list is not opt-in, state clearly that the content of your message is an advertisement, solicitation or commercial message; 9) don't harvest or scrape addresses from the web; 10) don't provide addresses to third parties without express permission (Parkin, 2009)."

Having this in mind, brilliance of advertising campaigns was in the way they were made meaningful to get the permission of consumers for propagating some idea. It is considerably easier for consumers to filter and throw out irrelevant messages and more and more difficult for advertisers to find their way to consumers by classical approaches. In classical media, timeliness, context or relevance of message is almost never in congruence with actual consumers' interests. Advertisers may never know whether intrusive advertisements distance people from traditional media or whether they do that because they like to have a greater control in using the media. The Internet introduces "on line" regime in making connections with consumers. This fact presupposes that advertisers have to be more creative and innovative.

It is a mistake to think that there is nothing new in advertising by Internet. Some people look at the Internet as the same marketing mechanism as the ones used in the past but based on digital steroids. This is a dangerous, limited and short-sighted view. The crucial change has occurred in the way in which advertisers act 
together with consumers. The main advantage of the Internet is that it stimulates communication between equal parts (peer-to-peer) to the extent that previously was not possible. In advertising by Internet, failure is a mere consequence of the incapacity of advertisers to rethink their advertising models. In order to survive, companies - all their employees and not only marketing managers - have to learn how to establish an interactive relation with consumers in such a way that is quite opposite from what was appropriate even five years ago.

Building relations with consumers by Internet is the future of advertising. It is not about new media models or new tools. It is about connecting people by two-way communication. Advertisers must aspire to understand the other person and not only to control his/her behavior. Internet is a mighty device in establishing ethical relations between advertisers and consumers. And this is in accordance with the old Roman maxim - bona fides.

\section{Description and the results of the research}

The empirical research included 214 subjects who answered the poll questions through the Internet. The questionnaire consisted of 20 questions that were categorized in 4 groups: 1) general data; 2) data about the Internet use; 3) purchasing through the Internet; and 4) confidence in advertising by Internet. The last question was related to the respondents' experience in similar polls. This time we shall present some interesting results.

Since the questions were qualitative, we used a chi-square test contingency table. The poll has shown that the employment status significantly predefines the purpose of the Internet use $(\mathrm{LI}=99.146, \mathrm{df}=4, \mathrm{p}<.001$; Cramer's $V=.435, p<.001$ ). While $62.8 \%$ of the unemployed use the Internet for entertainment, $46.3 \%$ of the employed do the same, the rest of the employed use the Internet in the first place for their job.

The employment status also significantly predefines why people decide to buy through the Internet $(\mathrm{LI}=14.109, \mathrm{df}=4, \mathrm{p}<.01$; Cramer's $\mathrm{V}=.297, \mathrm{p}<.014)$. It is indicative that unemployed consumers are attracted by advertisement charm $-64 \%$. On the other side, only $12 \%$ of the unemployed decide to buy through the Internet because of curiosity, while the number of the employed in this case is $54.5 \%$.

Another issue the employment status also significantly predefines is the kind of products people buy through the Internet $(\mathrm{LI}=14.605, \mathrm{df}=4, \mathrm{p}<.01$; Cramer's $\mathrm{V}=.268, \mathrm{p}<.037), 60 \%$ of the unemployed buy entertainment products, while the number of employed in this regard is only $36.4 \%$.

The average time that people spend on the Internet also has an impact upon whether they purchase through the Internet $(\mathrm{LI}=13.936$, df $=4, \mathrm{p}<.01$; Cramer's $\mathrm{V}=.181, \mathrm{p}<.01)$. It is amazing that people who spend less than one hour on the Internet buy more than people who spend more time on the Internet $(54,5 \%$ vs. $21.6 \%+5.4 \%$ vs. $29.0 \%+1.9 \%)$.

The average time that people spend on the Internet has impact on the kind of product they purchase through the Internet $(\mathrm{LI}=16.695, \mathrm{df}=4, \mathrm{p}=<.01$; Cramer's $\mathrm{V}=.325, \mathrm{p}<.01)$. People who use the Internet more than 2 hours daily, buy more products for entertainment than people who spend less than 1 hour $(27.8 \%)$ and people who spend 1-2 hours on the Internet (45\%).

The average time that people spend on the Internet has an implication on the fact how people gain confidence in an advertiser on the Internet $(\mathrm{LI}=21.036 \mathrm{df}=6, \mathrm{p}<.01$; Cramer's $\mathrm{V}=.331, \mathrm{p}=<.016)$. In this case the previous experience is less important - reported by only $7 \%$, while the persuasiveness of advertisement is most important $-50.7 \%$.

The purpose of the Internet use and purchasing through the Internet are connected $(\mathrm{LI}=12.819, \mathrm{df}=4, \mathrm{p}$ $=<.012$; Cramer's $\mathrm{V}=.157, \mathrm{p}<=.033$ ) - people who primarily use the Internet for their job buy more than others.

The purpose of the Internet use is also connected with the fact why people decide to purchase through the Internet $(\mathrm{LI}=14.521, \mathrm{df}=4, \mathrm{p}<.001$; Cramer's $\mathrm{V}=.318, \mathrm{p}<.01$, in this case the persuasiveness of the advertisement is crucial for making a decision as to purchasing through the Internet $-45.1 \%$. 
Reading advertising messages on the Internet has a significant impact on whether people purchase through the Internet $(\mathrm{LI}=14.688 \mathrm{df}=4, \mathrm{p} .001$; Cramer's $\mathrm{V}=.177, \mathrm{p}=.01)$. The analysis demonstrates that people who purchase through the Internet gain confidence in the advertiser on the Internet primarily on the basis of the advertisement persuasiveness $-50.7 \%$, while the next item is friend's recommendation $-23.9 \%$.

It has also been shown that the reason why people decide to purchase through the Internet has a significant impact on the way of gaining confidence in advertisers on the Internet $(\mathrm{LI}=23.967, \mathrm{df}=6, \mathrm{p}<.001$; Cramer's $V=.472, p<.001)$. The satisfaction with purchasing through the Internet has a significant impact upon people's opinion about ethical rightness of advertising by Internet $(\mathrm{LI}=37.903, \mathrm{df}=6, \mathrm{p}<.001$; Cramer's $V=.483, p<.001)$. In this case, unsatisfied buyers regard advertisements as unethical because they offer a deceptive picture about a product/service - as many as $69.2 \%$.

People's opinion about the purpose of advertisement on the Internet has a significant influence on their views as regards the ethical rightness of advertising on the Internet $(L I=6.110, d f=1, p<.001$; Cramer's $V=.902, p<.001)$. In this case it is obvious that people who think that the purpose of advertisement is to offer a truthful information about a product/service in $92.9 \%$ cases regard advertisement as ethical, while quite an opposite opinion is expressed by those who have in mind that the function of advertisement is to convince people to buy some product/service - even $96.9 \%$ of them regard advertisement as unethical.

\section{Conslusion}

From the very beginning, advertising has not changed its twofold mission: to inform consumers and to convince them to buy a product/service that is advertised. The advertising media are morally neutral but the content of advertising can be value oriented.

Postmodern theorists denuded the nature of advertising pointing that it has become an object of consumption and serves to hide the basic relations of exploitation in the modern society. Moreover, advertizing does it globally and thus serves as a main support to the actual economic system that advocates values of consumerism.

So far, advertising has mostly been a one-way communication. Consumers have not had an opportunity to react to advertising. The whole transaction has been based on the confidence that customers have in advertising and this has been frequently misused.

The emergence of the Internet puts the ethics of advertising into a sharp focus. Owing to the Internet, a two-way communication can foster advertising, but if this is unethical, the advertiser may experience a catastrophe due to a prompt reaction from the virtual public. The Internet restores confidence of consumers in advertising and practically is the most democratic device for establishing the ethics of advertising.

Our investigation confirmed this changing nature of advertising by Internet and pointed out the necessity for modern companies to adjust their business philosophy and to include consumers in the creation of marketing campaigns as well as in advertising itself.

\section{REFERENCES}

[1] Baudrillard, Jean - The consumer society, London: Sage, 1997.

[2] Baudrillard, Jean - The System of Objects, London: Verso, 2005:178 - 191.

[3] Beauchamp, Tom - Manipulative Advertising, in: Tom L. Beauchamp and Norman E. Bowie - Ethical Theory and Business, Englewood Cliffs, NJ: Prentice Hall, 1988, pp. 421-430.

[4] Belgiovane, R. and Milne, J. (eds) (1996) The Globe report, Sydney, Australia Internet: http:/www.globe.com.au/globereport 210396.html\#a, March 21.

[5] Beltramini, Richard. F - Advertising Ethics: The Ultimate Oxymoron? Journal of Business Ethics 48: 215-216, 2003.

[6] Crane, A. and Matten, D. - Business Ethics, Oxford: Oxford University Press, 2007:336.

[7] Dickinson, R.A. and Carsky, M.L. - The consumer as an economic voter. In: R. Harrison, T. Newholm and D. Shaw (eds), The ethical consumer, London: Sage, 2000:36. 
[8] Hackley, C. - The meaning of ethics in advertising, Business Ethics: A European Review, 1999, Volume 8, Number 1, pp. 37-42.

[9] Hayek, A. F. - The Non Sequitur of the "Dependence Effect", Southern Economic Journal, April 1961.

[10] Packard, Vance - The Hidden Persuaders, New York: David McKay, 1957.

[11] Parkin, Godfrey - Digital marketing, London: New Holland Publishers, 2009: 185.

Receieved: May 2014. Accepted: August 2014.

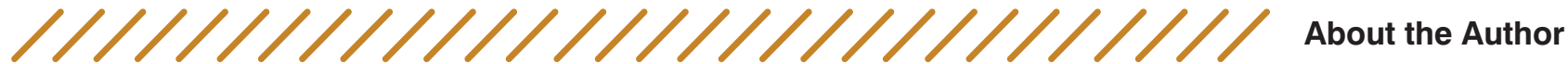

\section{Dušan Ljubičić \\ Belgrade Business School, Serbia dusan.ljubicic@bbs.edu.rs}

Born in Belgrade in 1961, Dušan Ljubičić received his B.Sc and M.Sc. degrees at the Faculty of Organizational Sciences, University of Belgrade. Since 1982 he works at the Belgrade Business School where he teaches the course in Information technology in business. 